\title{
Impact of molecular subtypes on the prediction of distant recurrence in estrogen receptor (ER) positive, human epidermal growth factor receptor 2 (HER2) negative breast cancer upon five years of endocrine therapy
}

Mark Laible ${ }^{1 *}$ D, Kerstin Hartmann ${ }^{1}$, Claudia Gürtler ${ }^{1}$, Tobias Anzeneder ${ }^{2}$, Ralph Wirtz ${ }^{3}$, Stephan Weber ${ }^{4}$, Thomas Keller ${ }^{4}$, Ugur Sahin ${ }^{1}$, Martin Rees ${ }^{5+}$ and Annette Ramaswamy ${ }^{6+}$

\begin{abstract}
Background: Current evidence suggests that patients with Luminal A early breast cancer can skip chemotherapy or extended endocrine therapy, but immunohistochemistry-based biomarker analysis for St Gallen subtyping may not be reproducible. We asked whether RT-qPCR can be used instead to address this clinical question.

Methods: RNA was extracted from tumor material derived from ER+/HER2- patients receiving adjuvant endocrine treatment for low-risk cancers and was semi-quantified by RT-qPCR with the MammaTyper ${ }^{\circledR}$. St Gallen subtypes were based on the mRNA expression of ERBB2/HER2, ESR1/ER, PGR/PR and MKI67/Ki67 after dichotomizing at predefined cut-offs. Differences in distant disease-free survival (DDFS) were assessed by Kaplan Meier analysis and Cox regression.

Results: With a median follow up of 7.8 years, there were ten events in the group of 195 Luminal A-like tumors (5.1\%) and 18 events in the remaining 127 tumors (14.1\%), consisting mostly of Luminal B-like cases $(N=119)$. Luminal A-like had significantly better DDFS over the entire follow-up period (HR 0.35, 95\% Cls $0.16-0.76, p=0.0078$ ) with a trend towards reduced probability of recurrences also in the late phase ( $>5$ years) (HR 0.20, $p=0.052$ ). The survival advantage spanning the entire follow-up period persisted in the pNO or pNO-N1 subgroups or after correcting for clinicopathological parameters. MKI67 alone significantly predicted for worse DDFS (HR 2.62, 95\% Cls $1.24-5.56, p=0.0088)$.

Conclusions: St Gallen Luminal A-like tumors identified by RT-qPCR display markedly low rates of distant recurrence at ten years follow-up. Patients with such tumors could be spared chemotherapy due to the obviously unfavourable benefit/toxicity ratio.
\end{abstract}

Keywords: Breast cancer, Luminal A-like, ER, MKI67, Ki67, Distant recurrence

\footnotetext{
* Correspondence: mark.laible@biontech.de

${ }^{\dagger}$ Martin Rees and Annette Ramaswamy contributed equally to this work.

${ }^{1}$ BioNTech Diagnostics GmbH, An der Goldgrube 12, 55131 Mainz, Germany

Full list of author information is available at the end of the article
}

(c) The Author(s). 2019 Open Access This article is distributed under the terms of the Creative Commons Attribution 4.0 International License (http://creativecommons.org/licenses/by/4.0/), which permits unrestricted use, distribution, and reproduction in any medium, provided you give appropriate credit to the original author(s) and the source, provide a link to the Creative Commons license, and indicate if changes were made. The Creative Commons Public Domain Dedication waiver (http://creativecommons.org/publicdomain/zero/1.0/) applies to the data made available in this article, unless otherwise stated. 


\section{Background}

The survival of patients who undergo surgery for earlystage estrogen receptor (ER)-positive/human epidermal growth factor receptor 2 (HER2)-negative breast cancers is heterogeneous. Whereas five years of endocrine treatment suffices for many women, others remain at significant risk of early or late distant recurrence warranting additional chemotherapy or extended endocrine therapy [1-3]. Accurate differentiation between these clinical subsets of early breast cancer impacts the health and quality of life of thousands of women worldwide and remains one of the most intensively investigated areas in the field of breast cancer biomarkers. Driving this campaign is the fact that calculation of recurrence risk by traditional clinicopathological prognostic factors such as histologic grade and Ki67 lacks necessary accuracy and reproducibility [4].

The discovery of a natural transcriptional architecture of breast cancer in the form of the "intrinsic" subtypes had a tremendous impact on the prognostic stratification of ER-positive/HER2-negative disease, showing that an accurate distinction between a low-risk Luminal A and a high-risk Luminal B group of tumors is possible by means of measuring gene expression [5, 6]. During the last two decades many gene expression assays have gradually entered the clinic as there is compelling evidence that their routine use refines residual risk estimates obtained by traditional clinicopathological risk factors alone [7].

Owing to increased costs of commercial multi-gene assays, global initiatives have proposed immunohistochemistry (IHC) as a means for approximating the biological signals stored within mRNA expression [8]. According to the updated 2013 St Gallen classification of breast cancer, "intrinsic" subtypes may be sufficiently profiled by ER, progesterone receptor (PR), HER2 and marker of proliferation Ki67 protein expression [9]. In this evolving concept, tumors whose growth depends on ER but not HER2 may be either Luminal A-like or Luminal B-like, with the two subtypes differing in their expression of PR and Ki67. The distinction can be used to guide treatment decisions in the adjuvant setting, with higher proliferation and lower ER activity (characteristic of Luminal B-like tumors) indicating decreased 5- or 10year (distant)-recurrence-free probabilities and increased benefit from chemotherapy and possibly extended endocrine therapy [2, 3].

Although more economical, the St Gallen subtypes are highly sensitive to the quality of local testing and scoring IHC practices. Efforts to raise quality standards are still ongoing particularly for Ki67, owing to the essential link between tumor proliferation and chemotherapy response, which however may be impossible to harness in practice due to inherent difficulties with
Ki67 scoring. [10, 11]. Overall, reproducibility studies have not yet provided clear guidance on the validity of Ki67 immunostaining and data drawn from actual routine samples is missing [12]. These shortcomings continue to stimulate the search for new prognostic biomarkers with enhanced analytical performance characteristics and economical profile.

In previous studies we have shown that St Gallen molecular subtyping is also informative when using reverse transcription quantitative real-time polymerase chain reaction (RT-qPCR) for measuring the mRNA expression of the 4 biomarkers, i.e. ER (ESR1), PR (PGR), HER2 (ERBB2) and Ki67 (MKI67) [13, 14]. Using predefined cut-off values for separating high from low (positive from negative) gene expression, the resulting subtypes are stable against various analytical perturbations across different laboratories and operators [15, 16]. Our approach leverages the analytical advantages of RTqPCR, to enable guideline-driven, standardized and interpretation-free breast cancer molecular classification. Herein we asked whether the subtypes obtained by MammaTyper ${ }^{\oplus}$ can stratify patients in prognostic subgroups in a cohort of clinical low-risk ER-positive/ HER2-negative breast cancers treated with standard 5-year endocrine therapy.

\section{Methods}

This is a retrospective observational study on formalinfixed paraffin-embedded tumor material provided by the non-profit organization PATH Biobank (http://www. path-biobank.org/index.php/en/about-path/) [17]. Inclusion criteria were the following: women diagnosed consecutively between 2005 and 2011 and treated with surgery and hormonal systemic therapy (no chemotherapy) in all seven certified breast cancer centers cooperating with PATH Biobank in Germany, adequate tumor material obtained during routine surgery and ERpositive/HER2-negative breast cancer assessed by local protocols.

The informed consent documents, especially regarding sample donation and data processing, were reviewed by the Bavarian State Office for Data Protection Supervision Authority and approved by the ethics committee of the Medical Faculty of the Rheinischen FriedrichWilhelms-Universität Bonn, Germany (vote number: 255/06). All participants gave written informed consent as per PATH Biobank policy.

Tumor cell content (TCC) was determined on a $3 \mu \mathrm{m}$ H\&E stained slide as the planimetric ratio of areas covered by invasive carcinoma in relation to areas covered by DCIS and non-neoplastic tissue. For samples with at least $20 \%$ TCC, RNA was extracted from a single $10 \mu \mathrm{m}$ section using the bead-based RNA purification kit (RNXtract ${ }^{\oplus}$, BioNTech Diagnostics $\mathrm{GmbH}$ ) according to 
Table 1 Translation of MammaTyper ${ }^{\circledR}$ single marker results into molecular subtypes according to St Gallen classification (2013)

\begin{tabular}{lllll}
\hline ERBB2 & ESR1 & PGR & MKI67 & St Gallen Subtype \\
\hline pos & pos & pos & pos & Luminal B-like (HER2 positive) \\
pos & pos & pos & neg & Luminal B-like (HER2 positive) \\
pos & pos & neg & pos & Luminal B-like (HER2 positive) \\
pos & pos & neg & neg & Luminal B-like (HER2 positive) \\
pos & neg & pos & pos & Not defined by St Gallen (ER-/PR+) \\
pos & neg & pos & neg & Not defined by St Gallen (ER-/PR+) \\
pos & neg & neg & pos & HER2 positive (non-luminal) \\
pos & neg & neg & neg & HER2 positive (non-luminal) \\
neg & pos & pos & pos & Luminal B-like (HER2 negative) \\
neg & pos & pos & neg & Luminal A-like \\
neg & pos & neg & pos & Luminal B-like (HER2 negative) \\
neg & pos & neg & neg & Luminal B-like (HER2 negative) \\
neg & neg & pos & pos & Not defined by St Gallen (ER-/PR+) \\
neg & neg & pos & neg & Not defined by St Gallen (ER-/PR+) \\
neg & neg & neg & pos & Triple negative (ductal) \\
neg & neg & neg & neg & Triple negative (ductal) \\
\hline
\end{tabular}

the manufacturers' instructions. For RT-qPCR, the MammaTyper in vitro diagnostic assay (BioNTech Diagnostics $\mathrm{GmbH}$ ) was used according to manufacturers' instructions on a CFX96 ${ }^{\mathrm{TM}}$ system (BioRad) using total RNA from RNXtract ${ }^{\circledR}$ eluates. A robust detection of the two reference genes CALM2 and B2M per pre- defined sample validity criteria was used as a quality control for the RNA samples. Gene expression levels for ERBB2, ESR1, PGR and MKI67 were categorized as being either positive or negative based on predefined cutoff values [18]. Thereafter, each case was classified according the St Gallen surrogate definitions for molecular subtypes (Table 1).

The main measure of outcome was distant disease-free survival (DDFS), defined as any recurrence at a distant organ. Deaths without prior documentation of recurrence were scored as censored events. The analysis was carried out in the entire population and separately in patients with node-negative breast cancer ( $\mathrm{pN} 0)$, or patients with 0 to 3 positive lymph nodes ( $\mathrm{pN} 0$ and $\mathrm{pN} 1$ ). In all analyses we considered patients whose tumors were classified as Luminal A-like as belonging to the low risk group, whereas the remaining subtypes were high risk. The principal objective was to compare the two prognostic subsets for the entire (0-10 years) and for the late (5-10 years) follow-up periods. In addition, we performed Cox regression to assess the value of the RNAbased St Gallen risk stratification compared to tumor size, nodal status and histologic grade. For this analysis, covariables were treated as continuously scaled parameters. Finally, we tested whether MKI67 as a single marker would suffice for prognostication.

Double pseudonymized clinicopathological data were sent directly from PATH Biobank to ACOMED Statistik (Leipzig, Germany) and were inaccessible by individuals

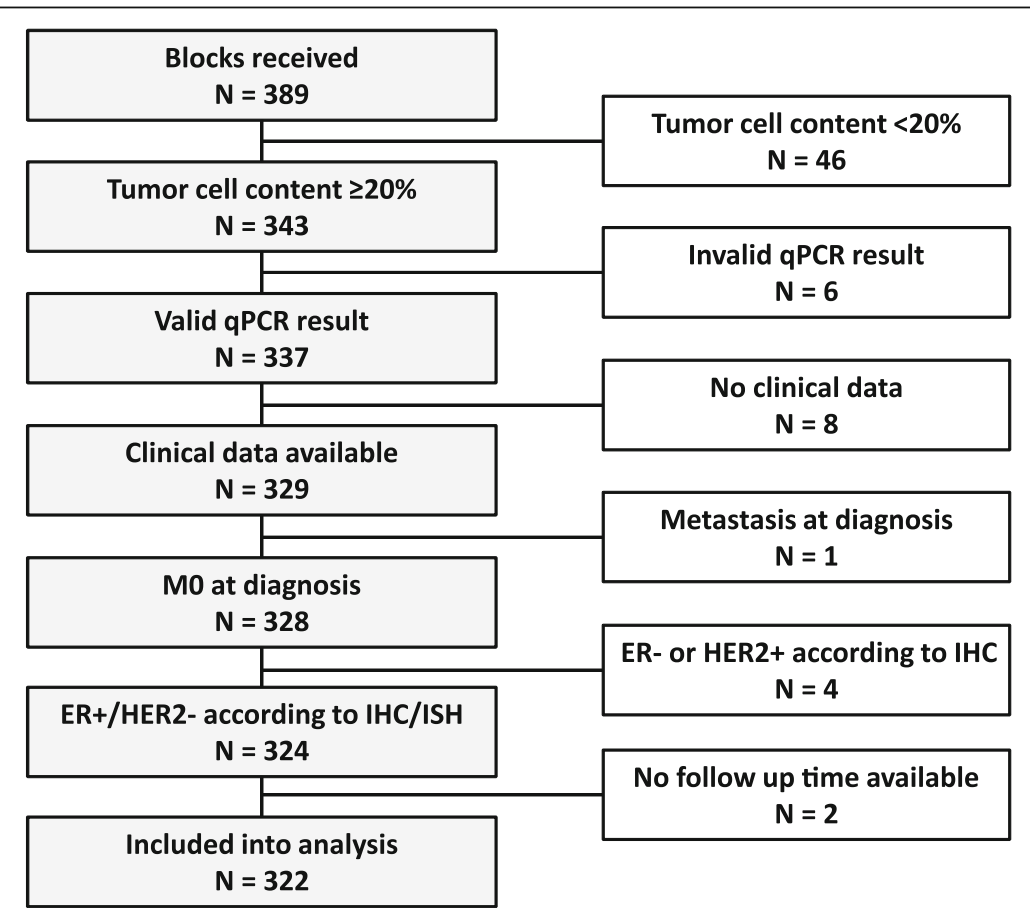

Fig. 1 Flow of sample selection and dropout: Most invalidated samples were due to insufficient tumor cell content. A minimum content of 20\% was applied in line with MammaTyper ${ }^{\circledast}$ published specifications [15] 
Table 2 Patient demographics and sample characteristics

\begin{tabular}{|c|c|c|}
\hline \multicolumn{3}{|l|}{ Age [years] } \\
\hline Min & \multicolumn{2}{|l|}{37.7} \\
\hline P25\% & \multicolumn{2}{|l|}{55.7} \\
\hline Median & \multicolumn{2}{|l|}{62.46} \\
\hline P75\% & \multicolumn{2}{|l|}{69.3} \\
\hline \multirow[t]{2}{*}{ Max } & \multicolumn{2}{|l|}{83.5} \\
\hline & $\mathrm{N}$ & $\%$ \\
\hline \multicolumn{3}{|l|}{ Menopausal status } \\
\hline Premenopausal & 32 & 9.9 \\
\hline Perimenopausal & 6 & 1.9 \\
\hline Postmenopausal & 258 & 80.1 \\
\hline NA & 26 & 8.1 \\
\hline \multicolumn{3}{|c|}{ Breast-conserving surgery } \\
\hline Yes & 279 & 86.6 \\
\hline No & 43 & 13.4 \\
\hline \multicolumn{3}{|l|}{ Histological subtype } \\
\hline Invasive ductal & 243 & 75.5 \\
\hline Invasive lobular & 63 & 19.6 \\
\hline Tubular & 7 & 2.2 \\
\hline Mucinous & 5 & 1.6 \\
\hline Others & 4 & 1.2 \\
\hline \multicolumn{3}{|l|}{ Tumor grading } \\
\hline G1 & 83 & 25.8 \\
\hline G2 & 224 & 69.6 \\
\hline G3 & 15 & 4.7 \\
\hline \multicolumn{3}{|l|}{ T-stage } \\
\hline pT 1a & 5 & 1.6 \\
\hline pT 1b & 72 & 22.4 \\
\hline pT 1c & 185 & 57.5 \\
\hline pT 2 & 56 & 17.4 \\
\hline p' 3 & 4 & 1.2 \\
\hline \multicolumn{3}{|l|}{$\mathrm{N}$-stage } \\
\hline $\mathrm{pN} 0$ & 278 & 86.3 \\
\hline $\mathrm{pN} 1 \mathrm{mic}$ & 13 & 4 \\
\hline $\mathrm{pN} 1 \mathrm{a}$ & 25 & 7.8 \\
\hline $\mathrm{pN} 2 \mathrm{a}$ & 2 & 0.6 \\
\hline pN 3a & 3 & 0.9 \\
\hline NA & 1 & 0.3 \\
\hline
\end{tabular}

generating MammaTyper ${ }^{\odot}$ results. All analyses were carried out in SAS 9.4. $P$-values $<0.05$ were considered significant.

\section{Results}

Cohort assembly and sample dropout are presented in Fig. 1. Median follow up was 7.8 years, during which 28 distant events occurred (8.5\%). Standard clinicopathological characteristics are listed in Table 2. This is a lowrisk cohort of mainly postmenopausal women with G12, pT1-2, pN0-1 invasive breast cancer consisting of primarily Luminal A-like (60.6\%) and Luminal B-like cancers (37\%). As expected, some discordance was found between original IHC classification and PCR, with 2 cases being reclassified as Luminal B-like (HER2 positive) and 4 as Triple negative. Women with Luminal Alike breast cancers were at low risk of developing a distant recurrence after ten years of follow-up (5.1\%), whereas in the group of Luminal B-like, $13.4 \%$ of cancers recurred with distant metastases (Table 3). The negative predictive value of the stratification was $94.9 \%$ (only ten patients out of 195 being classified as Luminal A-like would be expected to develop metastases within ten years).

In Kaplan-Meier analysis we observed a significant difference in ten-year DDFS between Luminal A-like and other subtypes grouped together as one (Fig. 2). Luminal A-like tumors were associated with $65 \%$ reduction of risk of distant recurrence compared to the non-Luminal Alike group (HR 0.35; CI 0.16-0.76, $\mathrm{p}=0.0078$ ). Estimates of HR were similarly significant when focusing on patients with 0-3 lymph nodes, when restricting the analysis to node-negative breast cancer patients or when the comparison was between Luminal A-like and Luminal $B$-like tumors (Table 4). In multivariable analysis, the prognostic information provided by the subtypes remained significant after adjusting for nodal status, tumor size and tumor grade (Table 5). T-stage was the only conventional parameter that remained significant in the final model.

The Luminal A-like subtype was a favourable prognostic indicator associated with a reduced probability of recurrences also in the late ( $>5$ years) follow-up period with an HR of 0.2. However, as shown by the wider CIs (0.041-1.015) and by the marginally significant $p$-value (0.052), this association lacked the strength observed over the entire follow-up period.

According to the St Gallen surrogate definitions of the molecular subtypes, Luminal B-like cancers consist of ER-positive tumors that either display high Ki67 irrespective of PR or alternatively lack both Ki67 and PR expression, illustrating the increased weight of tumor proliferation in this classification. For this reason, we further investigated whether MKI67 as a single marker could be used for stratifying patients into prognostic groups. High MKI67 expression was associated with a higher risk of distant recurrence over all patients $(N=$ 322, HR 2.62, 95\% CIs 1.24-5.56, $p=0.0088$ ) as well as in ESR1+/ERBB2- patients $(N=314$, HR 2.77, 95\% CIs 1.27-6.03, $p=0.0077$ ) (Fig. 3). In multivariable analysis in the ESR1+/ERBB2- set the MKI67 status and tumor 
Table 3 Distribution of MammaTyper ${ }^{\circledR}$ subtypes according to distant events

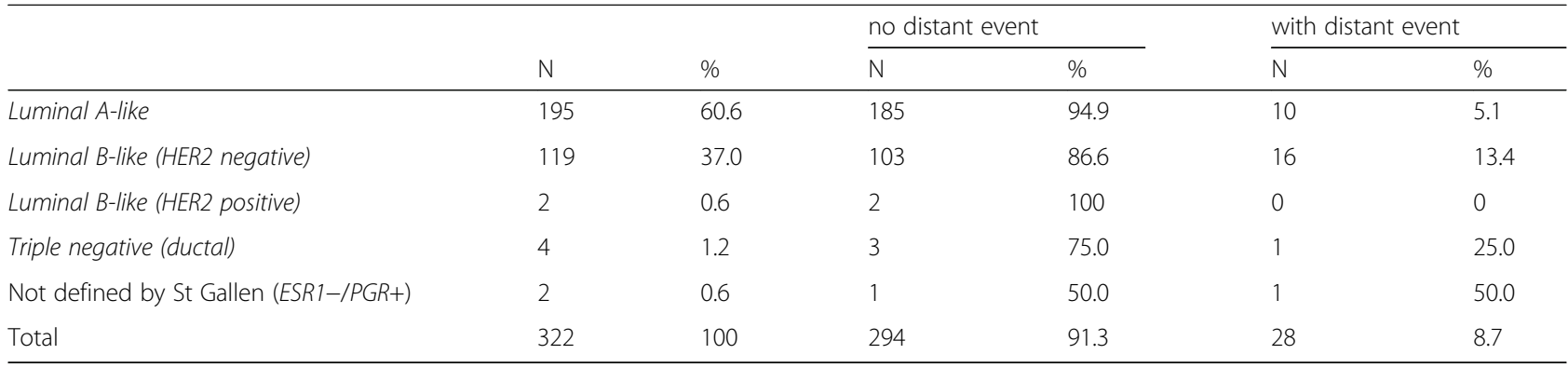

stage displayed almost identical hazard ratios, however only stage was clearly significant (Table 6).

\section{Discussion}

Estimating the prognosis of patients with early-stage ERpositive/HER2-negative breast cancer treated with standard 5-year endocrine therapy is essential for assessing the need for additional adjuvant systemic treatment. Herein we asked whether St Gallen definitions of molecular subtypes can be combined with RT-qPCR to successfully stratify patients in prognostic groups based on the expression of ERBB2, ESR1, PGR and MKI67 in their tumors. We show that the outcome of Luminal A-like tumors significantly differed from the rest of the cohort independent of conventional clinicopathological parameters and to such extent as to render benefit from adjuvant chemotherapy unlikely, especially when counting potential toxicities. These results reiterate the importance of St Gallen definitions of "intrinsic" subtypes, particularly the distinction between Luminal A-like and Luminal B-like cancers, for predicting the outcome of ER-positive disease and for assessing the need for adjuvant chemotherapy [3]. Interestingly, subtyping by RT-qPCR remained significant after correcting for clinicopathological variables, whereas MKI67 RNA expression alone did not, which is consistent with subtypes being more informative as they integrate several biological signals quantified by the individual markers.

The favourable prognosis of Luminal A breast cancers has been invariably demonstrated in diverse patient populations and treatment settings, including ER-positive low-risk cohorts [19-23]. Luminal A tumors are characterized by low proliferation and high expression of ERregulated genes and are thus resistant to cytotoxic therapy, as also illustrated by the lack of pathological complete response after neoadjuvant chemotherapy despite excellent 5-year survival rates [24]. Consequently, accurate and precise classification of the Luminal A subtype allows patients with such tumors to safely forego chemotherapy and be spared associated toxicities [2].

Stratifying tumors into Luminal A or Luminal B breast cancer, may also help predict the risk of distant recurrence at years 5-10 of follow-up by being prognostic in this timespan [25] and may thus serve as a biomarker

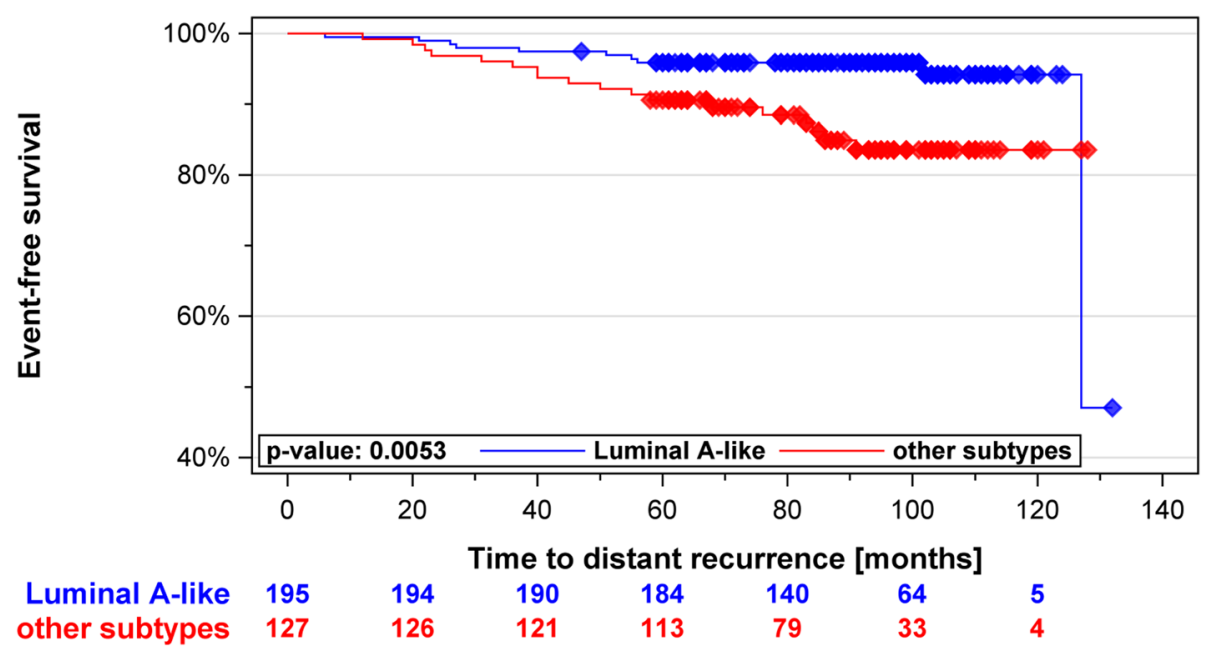

Fig. 2 Kaplan Meier curves of MammaTyper ${ }^{\circledR}$ Luminal A-like vs. other subtypes as one group: Luminal A-like cases were statistically significantly associated with better distant disease-free survival 
Table 4 Cox regression and log rank analysis: Luminal A-like vs. other subtypes

\begin{tabular}{llllll}
\hline & & & & & Hazard Ratio \\
Effect & Subset & Estimate & $95 \%$ Cls & $p$-value & $p$-value \\
\hline Luminal A-like vs. Other subtypes & all patients & 0.350 & $0.16-0.76$ & 0.0078 & 0.0053 \\
& $0-3$ positive nodes & 0.370 & $0.16-0.85$ & 0.0184 & 0.0141 \\
& node negative & 0.344 & $0.14-0.86$ & 0.0234 & 0.0177 \\
Luminal-A-like vs. Luminal B-like & all patients & 0.37 & $0.19-0.81$ & 0.0141 & 0.0106 \\
\hline
\end{tabular}

for or against endocrine treatment continuation [26]. In the present study, Luminal A-like tumors demonstrated a trend towards improved outcomes in the late followup period; however, results did not reach statistical significance. Prediction of recurrence risk during late follow-up remains an area of active investigation with evidence suggesting that some molecular profiling tests may per-design perform differently in this timespan [7]. More data will be needed to answer this question for the herein proposed RNA-based subtyping, as sample and event numbers in the corresponding subgroup analysis of years 5-10 was not enough for drawing a definite conclusion.

The ability of genomic assays for prognostication carried out under high quality standards and without bias from human interpretation often comes with a price tag, which in several parts of the world may be too high for both patients and health systems [8]. Affordable alternatives exploiting conventional clinicopathological parameters to approximate the output of gene-expression tests are therefore becoming popular [9, 27, 28]. In clinical reality however, parameters such as histologic grade and IHC for Ki67 or ER, regularly required as input, are still infested by significant levels of inter-observer variability [29-35]. Such shortcomings inevitably weaken the reallife utility of pathology-based proxies of molecular profiling, a challenge that could be overcome using biomarkers with an improved analytical performance record such as RT-qPCR.

Previously we have shown that St Gallen subtyping carried out with RNA- instead of protein expression significantly interacts with the benefit of docetaxel in the adjuvant setting and that MKI67 expression may enhance the prediction of pathological complete response [13, 14]. In the present work our approach successfully identified patients with luminal tumors whose risk of relapse at ten years is so low that benefit from chemotherapy would be unable to surpass the potential adverse effects. Alongside an expanding list of evidence on clinical validity, gene expression of ERBB2, ESR1, PGR, and MKI67 with RT-qPCR has a noticeable track record of both analytical precision and reproducibility in the context of decentralized biomarker testing $[15,16]$. These features may advocate an enhanced role of RT-qPCR in breast cancer biomarker testing.

Despite being subject to selection bias due to its retrospective nature, our study bears similarity to the TRANSATAC and ABCSG- 6 and -8 trial populations that were used to prospectively validate many prognostic gene signatures [36, 37]. Moreover, none of the patients received either chemotherapy or targeted therapy, while specimen archiving and data collection was carried out according to standard operating procedures. Nevertheless, a prospective study remains the golden standard for demonstrating the clinical validity of a biomarker and thus prospective validation should be the long-term goal for MammaTyper ${ }^{\circ}$. Additional strengths of our study are the use of predefined analysis methods, including cut-off values and the fact that subtypes were generated by investigators blinded to clinical variables or follow-up. A limitation of our work is that multivariable analysis did not include IHC data for Ki67, as these were not available by PATH Biobank due to the fact that Ki67 has not been a standard parameter in routine pathological testing throughout the diagnosis years of the patients included in this study. Lastly, due to the small number

Table 5 Multivariable Cox regression analysis for Tumor subtype Luminal A-like

\begin{tabular}{lllll}
\hline & & Hazard Ratio & & \\
\cline { 3 - 5 } Parameter & Effect & Estimate & $95 \%$ Cls & $0.180-0.959$ \\
\hline Tumor subtype Luminal A-like & Luminal-A-like & 0.415 & 0.0395 \\
T-stage & Increase by ' $+1^{\prime}$ & 2.137 & $1.201-3.802$ & 0.0098 \\
N-stage & Increase by '+ 1' & 1.540 & $0.933-2.539$ & 0.0910 \\
Tumor grade & Increase by '+1' & 1.897 & $0.778-4.627$ & 0.1591 \\
\hline
\end{tabular}




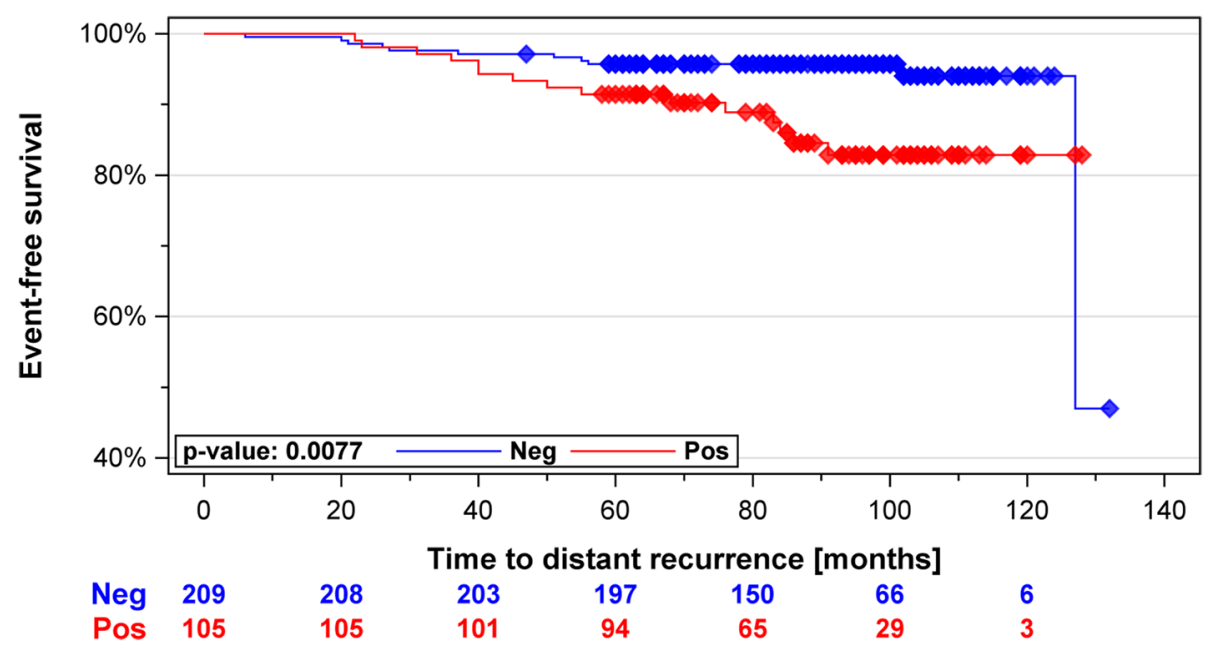

Fig. 3 Kaplan Meier curves of MammaTyper ${ }^{\oplus}$ MKI67 positive (high) vs. MKI67 negative (low) in ESR1+/ERBB2- tumors: MKI67 negative cases were statistically significantly associated with better distant disease-free survival

of patients with 1-3 lymph nodes, we were not able to test our hypothesis separately in this clinical subset. Even though the favourable effect of the Luminal Alike subtype remained constant between node-negative patients and the entire cohort, at this point it is not possible to conclude whether patients with 1-3 lymph nodes could be spared chemotherapy. Several gene expression prognostic tests such as MammaPrint ${ }^{\ominus}$, Oncotype DX ${ }^{\oplus}$ and Prosigna ${ }^{\oplus}$ have been studied extensively for years. The evidence provided by these studies shows that the prognostic information from different tests is broadly equivalent for the population of women with estrogen receptor -positive breast cancers. On the individual patient level however, the established tests may provide differing risk categorization and subtype information [38]. This observed disagreement raises the question how the test results impact treatment decisions for individual patients [38]. These concerns are one of the reasons why the patient and health economic benefits of the individual prognostic tests is still under intense discussion. The question of individual patient management therefore needs to be addressed in future research together with the question whether a low cost molecular assay measuring fewer parameters may provide similar

Table 6 Multivariable Cox regression analysis for MKI67 low/high

\begin{tabular}{lllll}
\hline & & \multicolumn{3}{l}{ Hazard Ratio } \\
\cline { 3 - 5 } Parameter & Effect & Estimate & $95 \%$ Cls & $p$-value \\
\hline MKI67 Positive (high) & Positive & 2.270 & $0.986-5.226$ & 0.0541 \\
T-stage & Increase by '+ 1' & 2.273 & $1.274-4.052$ & 0.0054 \\
N-stage & Increase by '+ 1' & 1.401 & $0.819-2.399$ & 0.2187 \\
Tumor grading & Increase by '+ 1' & 2.111 & $0.814-5.478$ & 0.1245 \\
\hline
\end{tabular}

prognostic information while being accessible to a broader range of patients.

\section{Conclusions}

Using RNA instead of protein profiles to classify tumors according to the St Gallen surrogate definitions of molecular subtypes provides independent prognostic information in early-stage ER-positive/HER2-negative breast cancer. Luminal A-like tumors displayed markedly low rate of distant recurrence at ten years of follow-up, indicating lack of benefit from the addition of chemotherapy. Given the importance of MKI67 in separating Luminal A-like from Luminal B-like tumors, our study lends further support to the clinical significance of tumor proliferation and particularly MKI67 gene expression for the management of breast cancer.

\section{Abbreviations}

DDFS: Distant disease-free survival; ER: Estrogen receptor; ERBB2: Epidermal growth factor receptor 2; ESR1: Estrogen receptor 1; FFPE: Formalin-fixed paraffin-embedded; H\&E: Hematoxylin and eosin; HER2: Epidermal growth factor receptor 2; IHC: Immunhistochemistry; MKI67: Marker of proliferation Ki-67; mRNA: messenger RNA; PATH: Patients' Tumor Bank of Hope; PGR: Progesterone receptor; PR: Progesterone receptor; RNA: Ribonucleic acid; RT-qPCR: Reverse transcription quantitative real-time PCR; TCC: Tumor cell content

\section{Acknowledgements}

We thank the Gynecologists and Pathologists at the breast cancer centers in Germany working for PATH Biobank as sample source sites for their help in allocating samples and data. Furthermore we thank all patients who were willing to donate their samples and data - without their support the research work would not be possible. We thank Jeanette Reimann-Kreft for review of tissue slides. We also thank Katharina Kaiser, Daniela Weiser and Lukas Krimmer for excellent technical assistance and Sotirios Lakis for providing medical writing services.

Authors' contributions

ML, TA, US, RW, MR and AR conceived and designed the study. CG supported MammaTyper data acquisition. ML analyzed the MammaTyper 
data. $\mathrm{KH}$ reviewed the histomorphologic and immunohistochemical data. TA coordinated tissue allocation and collected clinical data. ML, SW and TK conducted the statistical analysis. All authors helped draft, reviewed and approved the final manuscript.

\section{Funding}

Funding for design of study, collection of samples, analysis and interpretation of data, writing of publication: BioNTech Diagnostics $\mathrm{GmbH}$.

\section{Availability of data and materials}

The datasets used and/or analyzed during the current study are available from the corresponding author on reasonable request.

\section{Ethics approval and consent to participate}

All procedures performed in studies involving human participants were in accordance with the ethical standards of the institutional and/or national research committee and with the 1964 Helsinki declaration and its later amendments or comparable ethical standards.

Informed consent was obtained from all individual participants included in the study. The informed consent documents, especially regarding sample donation and data processing, were reviewed by the Bavarian State Office for Data Protection Supervision Authority and approved by the ethics committee of the Medical Faculty of the Rheinischen Friedrich-WilhelmsUniversität Bonn, Germany (vote number: 255/06). All participants gave written informed consent as per PATH Biobank policy.

\section{Consent for publication}

Not applicable.

\section{Competing interests}

ML, KH, CG, US: Salary and stock ownership BioNTech Diagnostics GmbH / BioNTech AG. RW: Renumeration and consultancy/advisory role BioNTech Diagnostics $\mathrm{GmbH}$, Stock ownership Stratifyer Molecular Pathology $\mathrm{GmbH}$. SW, TK: Renumeration for statistical analyses BioNTech Diagnostics GmbH. All other authors declare that they have no conflicts of interest.

\section{Author details}

${ }^{1}$ BioNTech Diagnostics GmbH, An der Goldgrube 12, 55131 Mainz, Germany. ${ }^{2}$ PATH Biobank, Schäftlarnstr. 62, 81337 Munich, Germany. ${ }^{3}$ Stratifyer Molecular Pathology GmbH, Werthmannstr. 1c, 50935 Köln, Germany. ${ }^{4}$ ACOMED Statistik, Fockestraße 57, 04275 Leipzig, Germany. ${ }^{5}$ Gemeinschaftspraxis für Pathologie, Brustzentrum am St.-Johannes-Hospital, Amalienstraße 21, 44137 Dortmund, Germany. ${ }^{6}$ Institut für Pathologie, Universitätsklinikum Giessen und Marburg, Baldingerstraße, 35043 Marburg, Germany.

Received: 20 December 2018 Accepted: 27 June 2019

Published online: 15 July 2019

\section{References}

1. Gnant M, Steger GG. Fighting overtreatment in adjuvant breast cancer therapy. Lancet. 2009;374(9707):2029-30.

2. Senkus E, Kyriakides S, Ohno S, Penault-Llorca F, Poortmans P, Rutgers E, et al. Primary breast cancer: ESMO clinical practice guidelines for diagnosis, treatment and follow-up. Ann Oncol. 2015;26(Suppl 5):v8-30.

3. Untch M, Huober J, Jackisch C, Schneeweiss A, Brucker SY, Dall P, et al. Initial treatment of patients with primary breast Cancer: evidence, controversies, consensus: Spectrum of opinion of German specialists at the 15th international St. Gallen breast Cancer conference (Vienna 2017). Geburtshilfe Frauenheilkd. 2017;77(6):633-44.

4. Duffy MJ, Harbeck N, Nap M, Molina R, Nicolini A, Senkus E, et al. Clinical use of biomarkers in breast cancer: updated guidelines from the European group on tumor markers (EGTM). Eur J Cancer. 2017;75:284-98.

5. Prat A, Pineda E, Adamo B, Galván P, Fernández A, Gaba L, et al. Clinical implications of the intrinsic molecular subtypes of breast cancer. Breast. 2015;24(Suppl 2):S26-35.

6. Alfarsi L, Johnston S, Liu D, Rakha E, Green AR. Current issues with luminal subtype classification in terms of prediction of benefit from endocrine therapy in early breast cancer. Histopathology. 2018.

7. Sestak I, Buus R, Cuzick J, Dubsky P, Kronenwett R, Denkert C, et al. Comparison of the performance of 6 prognostic signatures for estrogen receptor-positive breast Cancer: a secondary analysis of a randomized clinical trial. JAMA Oncol. 2018;4(4):545-53.

8. Coates AS, Winer EP, Goldhirsch A, Gelber RD, Gnant M, Piccart-Gebhart M, et al. Tailoring therapies--improving the management of early breast cancer: St Gallen international expert consensus on the primary therapy of early breast Cancer 2015. Ann Oncol. 2015;26(8):1533-46.

9. Goldhirsch A, Winer EP, Coates AS, Gelber RD, Piccart-Gebhart M, Thürlimann $B$, et al. Personalizing the treatment of women with early breast cancer: highlights of the St Gallen international expert consensus on the primary therapy of early breast Cancer 2013. Ann Oncol. 2013;24(9):2206-23.

10. Prat A, Cheang MCU, Martín M, Parker JS, Carrasco E, Caballero R, et al. Prognostic significance of progesterone receptor-positive tumor cells within immunohistochemically defined luminal a breast cancer. J Clin Oncol. 2013; 31(2):203-9.

11. Polley MC, Leung SCY, Gao D, Mastropasqua MG, Zabaglo LA, Bartlett JMS, et al. An international study to increase concordance in Ki67 scoring. Mod Pathol. 2015;28(6):778-86.

12. Leung SCY, Nielsen TO, Zabaglo L, Arun I, Badve SS, Bane AL, et al. Analytical validation of a standardized scoring protocol for Ki67: phase 3 of an international multicenter collaboration. NPJ Breast Cancer. 2016;2:16014.

13. Wirtz RM, Sihto H, Isola J, Heikkilä $P$, Kellokumpu-Lehtinen $P$, Auvinen $P$, et al. Biological subtyping of early breast cancer: a study comparing RT-qPCR with immunohistochemistry. Breast Cancer Res Treat. 2016;157(3):437-46.

14. Sinn H, Schneeweiss A, Keller M, Schlombs K, Laible M, Seitz J, et al. Comparison of immunohistochemistry with PCR for assessment of ER, PR, and $\mathrm{Ki}-67$ and prediction of pathological complete response in breast cancer. BMC Cancer. 2017;17(1):124.

15. Laible M, Schlombs K, Kaiser K, Veltrup E, Herlein S, Lakis S, et al. Technical validation of an RT-qPCR in vitro diagnostic test system for the determination of breast cancer molecular subtypes by quantification of ERBB2, ESR1, PGR and MKI67 mRNA levels from formalin-fixed paraffinembedded breast tumor specimens. BMC Cancer. 2016;16:398.

16. Varga Z, Lebeau A, Bu H, Hartmann A, Penault-Llorca F, Guerini-Rocco E, et al. An international reproducibility study validating quantitative determination of ERBB2, ESR1, PGR, and MKI67 mRNA in breast cancer using MammaTyper ${ }^{\oplus}$. Breast Cancer Res. 2017;19(1):55.

17. Waldmann A, Anzeneder T, Katalinic A. Patients and methods of the PATH biobank - a resource for breast Cancer research. Geburtshilfe Frauenheilkd. 2014;74(4):361-9.

18. Gürtler C, Laible M, Schwabe W, Steinhäuser H, Li X, Liu S, et al. Transferring a quantitative molecular diagnostic test to multiple real-time quantitative PCR platforms. J Mol Diagn. 2018;20(4):398-414.

19. Nielsen TO, Parker JS, Leung S, Voduc D, Ebbert M, Vickery T, et al. A comparison of PAM50 intrinsic subtyping with immunohistochemistry and clinical prognostic factors in tamoxifen-treated estrogen receptor-positive breast cancer. Clin Cancer Res. 2010;16(21):5222-32.

20. Dowsett M, Sestak I, Lopez-Knowles E, Sidhu K, Dunbier AK, Cowens JW, et al. Comparison of PAM50 risk of recurrence score with oncotype DX and IHC4 for predicting risk of distant recurrence after endocrine therapy. J Clin Oncol. 2013;31(22):2783-90.

21. Gnant M, Filipits M, Greil R, Stoeger H, Rudas M, Bago-Horvath Z, et al. Predicting distant recurrence in receptor-positive breast cancer patients with limited clinicopathological risk: using the PAM50 risk of recurrence score in 1478 postmenopausal patients of the ABCSG-8 trial treated with adjuvant endocrine therapy alone. Ann Oncol. 2014;25(2):339-45.

22. Chen J, Jiang P, Wang H, Zhang J, Xu Y, Guo M, et al. The efficacy of molecular subtyping in predicting postoperative recurrence in breastconserving therapy: a 15-study meta-analysis. World J Surg Oncol. 2014; $12: 212$.

23. Viale G, de SFA, Slaets L, Bogaerts J, van 't Veer L, Rutgers EJ, et al. Immunohistochemical versus molecular (BluePrint and MammaPrint) subtyping of breast carcinoma. Outcome results from the EORTC 10041/BIG 3-04 MINDACT trial. Breast Cancer Res Treat. 2018;167(1):123-31.

24. Glück S, de SF, Peeters J, Stork-Sloots L, Somlo G. Molecular subtyping of early-stage breast cancer identifies a group of patients who do not benefit from neoadjuvant chemotherapy. Breast Cancer Res Treat. 2013; 139(3):759-67.

25. Filipits $M$, Nielsen TO, Rudas $M$, Greil $R$, Stöger $H$, Jakesz $R$, et al. The PAM50 risk-of-recurrence score predicts risk for late distant recurrence after endocrine therapy in postmenopausal women with endocrine-responsive early breast cancer. Clin Cancer Res. 2014;20(5):1298-305. 
26. Dowsett M, Sestak I, Regan MM, Dodson A, Viale G, Thürlimann B, et al. Integration of clinical variables for the prediction of late distant recurrence in patients with estrogen receptor-positive breast Cancer treated with 5 years of endocrine therapy: CTS5. J Clin Oncol. 2018;36(19):1941-8.

27. Lux MP, Nabieva N, Hildebrandt T, Rebscher H, Kümmel S, Blohmer J, et al. Budget impact analysis of gene expression tests to aid therapy decisions for breast cancer patients in Germany. Breast. 2018;37:89-98.

28. Klein ME, Dabbs DJ, Shuai Y, Brufsky AM, Jankowitz R, Puhalla SL, et al. Prediction of the Oncotype DX recurrence score: use of pathologygenerated equations derived by linear regression analysis. Mod Pathol. 2013;26(5):658-64.

29. McCullough AE, Dell'orto P, Reinholz MM, Gelber RD, Dueck AC, Russo L, et al. Central pathology laboratory review of HER2 and ER in early breast cancer: an ALTTO trial BIG 2-06/NCCTG N063D (Alliance) ring study. Breast Cancer Res Treat. 2014:143(3):485-92.

30. Pinder SE, Campbell AF, Bartlett JMS, Marshall A, Allen D, Falzon M, et al. Discrepancies in central review re-testing of patients with ER-positive and HER2-negative breast cancer in the OPTIMA prelim randomised clinical trial. Br J Cancer. 2017;1 16(7):859-63.

31. Varga Z, Diebold J, Dommann-Scherrer C, Frick H, Kaup D, Noske A, et al. How reliable is Ki-67 immunohistochemistry in grade 2 breast carcinomas? A QA study of the Swiss working Group of Breast- and Gynecopathologists. PLoS One. 2012;7(5):e37379.

32. Raap M, Ließem S, Rüschoff J, Fisseler-Eckhoff A, Reiner A, Dirnhofer S, et al. Quality assurance trials for Ki67 assessment in pathology. Virchows Arch. 2017:471(4):501-8

33. Laenkholm A, Grabau D, Møller Talman M, Balslev E, Bak Jylling AM, Tabor $T$, et al. An inter-observer Ki67 reproducibility study applying two different assessment methods: on behalf of the Danish scientific Committee of Pathology, Danish breast cancer cooperative group (DBCG). Acta Oncol. 2018;57(1):83-9.

34. Focke CM, Bürger $H$, van Diest PJ, Finsterbusch $K$, Gläser D, Korsching E, et al. Interlaboratory variability of Ki67 staining in breast cancer. Eur J Cancer. 2017;84:219-27.

35. Denkert C, Budczies J, von Minckwitz G, Wienert S, Loibl S, Klauschen F. Strategies for developing Ki67 as a useful biomarker in breast cancer. Breast. 2015;24(Suppl 2):S67-72

36. Sgroi DC, Sestak I, Cuzick J, Zhang Y, Schnabel CA, Schroeder B, et al. Prediction of late distant recurrence in patients with oestrogen-receptorpositive breast cancer: a prospective comparison of the breast-cancer index (BCI) assay, 21-gene recurrence score, and IHC4 in the TransATAC study population. The Lancet Oncology. 2013;14(11):1067-76.

37. Dubsky P, Filipits M, Jakesz R, Rudas M, Singer CF, Greil R, et al. EndoPredict improves the prognostic classification derived from common clinical guidelines in ER-positive, HER2-negative early breast cancer. Ann Oncol. 2013;24(3):640-7.

38. Bartlett JMS, Bayani J, Marshall A, Dunn JA, Campbell A, Cunningham C, et al. Comparing breast Cancer multiparameter tests in the OPTIMA prelim trial: no test is more equal than the others. J Natl Cancer Inst. 2016;108(9).

\section{Publisher's Note}

Springer Nature remains neutral with regard to jurisdictional claims in published maps and institutional affiliations.

Ready to submit your research? Choose BMC and benefit from:

- fast, convenient online submission

- thorough peer review by experienced researchers in your field

- rapid publication on acceptance

- support for research data, including large and complex data types

- gold Open Access which fosters wider collaboration and increased citations

- maximum visibility for your research: over $100 \mathrm{M}$ website views per year

At $\mathrm{BMC}$, research is always in progress.

Learn more biomedcentral.com/submissions 